\title{
A LITERATURA AFRO-BRASILEIRA E A EXPERIÊNCIA EM OFICINAS DO PIBID
}

\author{
Reginaldo Silva Araujo \\ Roseli Xavier do Nascimento ${ }^{2}$ \\ Filismina Fernandes Saraiva ${ }^{3}$ \\ Gildeci de Oliveira Leite 4
}

\begin{abstract}
RESUMO: A Literatura Afro-Brasileira é riquíssima e dispõe de diversas obras. O objetivo deste trabalho é relatar e analisar a experiência desenvolvida em oficinas do Núcleo de Iniciação à Docência (ID) "Literatura Afro-Brasileira e Baiana" do PIBID, ministradas para estudantes da 1 a série do ensino médio em Seabra-BA. Para tanto, foi constituído um corpus com poemas, imagens e slides utilizados para a apresentação da Literatura Afro-Brasileira. A análise é baseada em Duarte (2011) Guattari; Deleuze (2003), Brandão (2006) e Araujo (2018) e em textos literários de Conceição Evaristo (2008), Henrique Cunha Jr (1978) e Cristiane Sobral (2011). Os resultados obtidos evidenciam que os discentes, que pouco possuíam contato com o tema e autores, conseguiram assimilar o conceito e as características da Literatura Afro-Brasileira.
\end{abstract}

Palavras-Chave: Literatura Afro-Brasileira; PIBID; Oficinas.

ABSTRACT: Afro-Brazilian Literature is very rich and has several works. The objective of this work is to report and analyze the experience developed in workshops of the Nucleus of Initiation to Teaching (ID) "Afro-Brazilian and Bahian Literature" of PIBID, given to students of the 1st grade of high school in Seabra-BA.

Key words: Afro-Brazilian Literature; Teaching Initiation; Workshops.

\section{Introdução}

O presente trabalho relata a experiência desenvolvida em oficinas de Literatura Afro-Brasileira dentro do Núcleo de Iniciação à Docência (ID) "Literatura Afro-Brasileira e Baiana" do PIBID. O Pibid é o Programa Institucional de Bolsas de Iniciação à Docência, financiado pela Coordenação de Aperfeiçoamento de Pessoal de Nível Superior (CAPES) e aplicado em Núcleos de Iniciação à Docência (ID), formados por coordenadores,

\footnotetext{
${ }^{1}$ Graduando do curso de Licenciatura em Letras com Habilitação em Língua Portuguesa e Literaturas (UNEB/ Campus XXIII - Seabra/BA). Bolsista ID CAPES/UNEB XXIII - PIBID pelo Núcleo de ID “Literatura Afro-Brasileira e Baiana". Contato: r.araujosba@gmail.com

${ }^{2}$ Graduanda do curso de Licenciatura em Letras com Habilitação em Língua Portuguesa e Literaturas (UNEB/ Campus XXIII - Seabra/BA). Bolsista ID Voluntária - UNEB XXIII - PIBID pelo Núcleo de ID "Literatura AfroBrasileira e Baiana". Contato: rosarosexavier@gmail.com

${ }^{3}$ Mestra em Crítica Cultural (UNEB). Coordenadora do Núcleo de Iniciação à Docência "Literatura AfroBrasileira e Baiana" do PIBID/UNEB. Contato: filismina.saraiva@gmail.com

${ }^{4}$ Doutor em Difusão do Conhecimento (UFBA). Coordenador Voluntário do Núcleo de Iniciação à Docência "Literatura Afro-Brasileira e Baiana" do PIBID/UNEB. Contato: gildeci.leite@gmail.com
} 
- Revista de Iniciação à Docência, v. 5, n. 2, 2020 -

Publicação: agosto, 2020 - ISSN 2525-4332

supervisores e bolsistas. O projeto foi ministrado sob a forma de oficinas em escolas parceiras.

O Núcleo de ID "Literatura Afro-Brasileira e Baiana” do PIBID/UNEB, contou com a coordenação da Docente Ms. Filismina Fernandes Saraiva e coordenação voluntária do Prof. Dr. Gildeci de Oliveira Leite, aplicando oficinas nas seguintes escolas parceiras: Colégio Estadual Filinto Justiniano Bastos (CEFJB); Centro Estadual de Educação Profissional em Gestão e Negócios Letice Oliveira Maciel (CEEP - Letice Oliveira Maciel), ambas localizadas no município de Seabra - BA.

O objetivo deste relato é descrever e analisar a experiência realizada durante as oficinas no CEFJB, desenvolvida com estudantes da $1^{\mathrm{a}}$ série $B$ do ensino médio no mês de maio de 2019, ministradas por nós bolsistas de ID. As oficinas foram propostas sob a forma de discussão oral com os discentes e apresentação de slides ilustrados com textos literários, tópicos e imagens.

\section{Marco Teórico}

A Literatura Afro-Brasileira foi por muito tempo desvalorizada no Brasil. Contudo, hoje, está sendo valorizada e visibilizada em nosso país, sobretudo após a Lei 10.639/2003, que determinou a viabilização do estudo da história e cultura africana e afro-brasileira nas escolas brasileiras, entre outras demandas atualizadas pela Lei 11.645/2008. Diante disso, e como uma forma de discussão do conceito desta literatura tão rica em termos de obras e autores, recorreu-se neste trabalho aos aportes de Duarte (2011), Guattari ; Deleuze (2003), Brandão (2006) e Araujo (2018), como forma de buscar explicar o que é e quais autores fazem parte da literatura de cunho afro-brasileiro. Somando-se aos referidos teóricos, foram utilizados neste relato de experiência textos literários de Evaristo (2008), Cunha Jr (1978) e Sobral (2011).

\section{As oficinas: experiências com a Literatura Afro-Brasileira}

No dia 16 de maio de 2019, aplicamos a primeira oficina com o tema Literatura AfroBrasileira. Imaginávamos que os estudantes possuíssem poucos conhecimentos relacionados à temática. $E$ foi o que realmente verificamos a partir de questionamentos introdutórios desenvolvidos juntos aos alunos, como: O que é Literatura Afro-Brasileira? E quais autores fazem parte dessa literatura?

Grande parte da turma, composta por 40 estudantes, não conseguiu responder a essas perguntas iniciais. A partir disso, expusemos para os discentes da turma os conceitos relacionados a essa literatura. Conforme Duarte (2011) assinala, a Literatura Afro-Brasileira passou por um momento de questionamento, inclusive havia indagações no sentido de questionar a própria existência dessa variante literária. Entretanto, foi provado que ela existe e é também antiga, reconhecida desde os escritos de Domingos Caldas Barbosa e José do Nascimento Moraes, chegando a nomes contemporâneos como Conceição Evaristo, Cristiane Sobral, Wesley Correia e Lande Onawale. 
Os conceitos de Literatura Afro-Brasileira apresentado aos alunos durante a oficina foram aqueles propostos por Proença Filho (1988, p. 78 apud DUARTE, 2011, p. 378 - 379) e Damasceno (1988, p. 125 apud DUARTE, 2011, p. 378). Para o primeiro, a Literatura AfroBrasileira:

[...] será negra, em sentido restrito, uma literatura feita por negros ou descendentes assumidos de negros, e, como tal, reveladora de visões de mundo, de ideologias e de modos de realização que, por força de condições atávicas, sociais e históricas, se caracteriza por uma certa especificidade, ligada a um intuito claro de singularização cultural. Lato sensu, será a arte literária feita por quem quer que seja, desde que reveladora de dimensões peculiares aos negros ou aos descendentes de negros (PROENÇA FILHO, 1988 apud DUARTE, 2011, p. 378- 379).

Assim sendo, para o referido teórico, a Literatura Afro-Brasileira é aquela escrita por autores negros ou descendentes assumidos de negros ou não, mas que revele em sua temática a visão história, a sociedade e as condições que passaram e pela qual passam os negros e afrodescendentes em nosso país.

Damasceno (1988 apud DUARTE, 2011) corrobora com a visão lato sensu abordada por Proença Filho. Para ela, o importante é o tema, isto é, os textos relativos a essa perspectiva deveriam tratar das condições sociais, culturais e históricas dos negros.

Após este primeiro esclarecimento a respeito do conceito de Literatura AfroBrasileira, apresentamos as características dessa literatura segundo Duarte (2011). Os tópicos demarcados pelo autor são os seguintes: temática, autoria, ponto de vista, linguagem e público.

A temática expõe desde a delação do racismo, a falta de oportunidades para a população negra,

o resgate da história do povo negro na diáspora brasileira, passando pela denúncia da escravidão e de suas consequências ou ir à glorificação de heróis como Zumbi dos Palmares. [...] Abarca ainda as tradições culturais ou religiosas [...] destacando a riqueza dos mitos, lendas e de todo um imaginário circunscrito quase sempre à oralidade (DUARTE, 2011, p. 387).

Assim, estariam englobadas nesse tipo de literatura Conceição Evaristo, Wesley Correia, Lande Onawale, Lenice Gomes, entre outros autores. Esta última autora, em seu foco literário infantojuvenil no livro "Nina África: Contos de uma África menina para ninar gente de todas as idades", apresenta a valorização da natureza e das tradições culturais africanas (ARAUJO, 2018).

$\mathrm{Na}$ instância da autoria, insere-se uma discursividade marcada pela produção literária afro-brasileira com pertencimento étnico e identitário negro. Nesse fator, o relevante não está relacionado especificamente ao fenótipo do autor, mas na relação entre o escrito e a experiência negra, ou seja, aquilo que contemporaneamente a escritora Conceição Evaristo denomina de "escrevivência". A partir desse enfoque, ressaltamos aos discentes da oficina que Elisa Lucinda, Cristiane Sobral, Serafina Machado, Ana Maria Gonçalves estariam entre alguns nomes do cenário afro-brasileiro. 
Ao utilizar-se de um ponto de vista afro-brasileiro no texto literário, o autor/narrador/eu poético evidencia que apenas a "ascendência africana ou a utilização do tema são insuficientes. É necessário ainda a assunção de uma perspectiva identificada à história, à cultura, logo, toda problemática inerente à vida e às condições de existência [...] [dessa] população" (DUARTE, 2011, p. 391). Assim, o ponto de vista transparece nas entrelinhas da literatura, expondo a visão autoral e a ascendência africana.

Estreitamente relacionada às demais características, a linguagem é significativa na produção literária afro-brasileira. Nesse ponto, o vocabulário de origens africanas e a discursividade evidenciam uma semântica própria com ritmos e entonações (DUARTE, 2011) que apresentam uma desterritorialização e reterritorialização linguística e cultural (GUATTARI; DELEUZE, 2003). Ao abordar esse fator na oficina no CEFJB, chamamos a atenção dos estudantes para os inúmeros vocábulos do português do Brasil que possuem origem africana. Entre eles estão: angu, bagunça, batuque, berimbau, caçula, camundongo, canjica, farofa, mochila, quiabo, quilombo, samba e vatapá (BRANDÃO, 2006).

E a quinta característica, o público, é igualmente fundamental à Literatura AfroBrasileira. O público, tendo em vista que a grande maioria da população brasileira é negra, é destacado pela diferença cultural e pelo clamor da afirmação da identidade (DUARTE, 2011). Apresentar a variedade desse tipo de literatura e ao mesmo tempo combater preconceitos arraigados estiveram entre os objetivos do fator público e que foram destacados para turma na oficina do PIBID.

Segundo Duarte (2011), uma obra, para ser considerada pertencente à Literatura Afro-Brasileira, deve possuir estas cinco características umas somando-se às outras. Durante a explicitação dessas propriedades apresentamos os textos literários "Vozes Mulheres" de Conceição Evaristo (2008) e "Cabelos" de Henrique Cunha Jr. (1978).

O poema de Conceição Evaristo foi impactante para os alunos da turma. O quase relato do processo escravocrata brasileiro, que é esse poema, mostrou aos estudantes que a linguagem pode ser trabalhada, lavrada, reelaborando o real por meio das letras. 0 poema "Cabelos" de Henrique Cunha Jr. (1978) expôs a mudança de foco dos cabelos antes vítima de vários preconceitos por grande parte da sociedade.

Durante a execução das oficinas alguns dos estudantes fizeram perguntas interessantes, esclarecendo eventuais dúvidas. Notamos também que haviam alguns alunos que permaneceram quietos e outros ainda agitados, o que podia atrapalhar a atenção dos demais. Porém, chamando-os para os questionamentos e participação nas oficinas estes mudavam de postura. Grande parte da turma anotava as informações ditas por nós bolsistas de ID e disponibilizadas nos slides apresentados. 
- Revista de Iniciação à Docência, v. 5, n. 2, 2020 -

Publicação: agosto, 2020 - ISSN 2525-4332

\section{1 - Mãos a massa: a atividade}

Como uma produção oriunda das oficinas e uma maneira de verificação da aprendizagem, orientamos os estudantes para a leitura do texto "Pixaim", de Cristiane Sobral; e, em seguida, solicitamos que eles apontassem e justificassem os pontos que confirmam o pertencimento do referido texto à Literatura Afro-Brasileira, com base nas características apresentadas anteriormente.

Em um primeiro momento, fizemos a leitura do texto e os alunos, até então um pouco dispersos, fixaram suas atenções sobre as folhas impressas com o conto de Cristiane Sobral.

O conto aborda a história de uma narradora negra que sofreu discriminação racial, em especial pelos seus cabelos crespos (fato que intitula a obra). O que chama atenção é que as atitudes discriminatórias ocorreram por parte de sua mãe - que apresenta o fenótipo branco -, seus irmãos e vizinhos, os quais a queriam embranquecer. Há inclusive a narração de um episódio onde ocorreu a tentativa de um alisamento forçado das mechas do cabelo da criança que encarou tudo como uma "primeira vez [em que] foram violentadas as minhas raízes" (SOBRAL, 2011, p. 13 -14). Porém, o alisamento forçado dos cabelos a transformou em uma garota rebelde. Anos depois, ao fim do conto, o leitor é apresentado a uma "mulher madura de olhar doce e fértil" (ibid., p. 17) que aceita sua identidade afro-brasileira e sentencia: “a gente só pode ser aquilo que é” (ibid., p. 17).

$\mathrm{Na}$ aula seguinte, em 30/05/19, os discentes deram início à atividade. Pudemos esclarecer algumas dúvidas dos alunos a respeito das características da Literatura AfroBrasileira, ajudando e orientando-os no trabalho proposto. A atividade foi orientada pela introdução dos seguintes questionamentos:

Atividade - Oficina de Literatura Afro-Brasileira

UNIVERSIDADE DO ESTADO DA BAHIA
DCHT - CAMPUS XXIIII - SEABRA
COLÉGIO ESTADUAL FILINTO JUSTINIANO BASTOS
PROGRAMA INSTITUCIONAL DE BOLSAS DE INICIAÇÃO À DOCÊNCIA
(PIBID/UNEB)
NÚCLEO DE ID: “LITERATURA AFRO-BRASILEIRA E BAIANA”
BOLSISTAS DE ID:
ESTUDANTES:
TURMA: $\quad$ DATA: /
ATIVIDADE - OFICINA DE LITERATURA AFRO-BRASILEIRA


- Revista de Iniciação à Docência, v. 5, n. 2, 2020 -

Publicação: agosto, 2020 - ISSN 2525-4332

Após a leitura do texto "Pixaim" de Cristiane Sobral, aponte e
justifique os pontos que confirmam o pertencimento da obra à
Literatura Afro-Brasileira:
1- Qual é a temática do conto?
2- A autora é comprometida com questões sociais? Se destaca por
participar de obras que visibilizam a Literatura Afro-Brasileira,
como os "Cadernos Negros"?
3- Qual é o ponto de vista sobre o tema abordado pelo texto?
4- Linguagem: Como as palavras usadas foram usadas no sentido
pejorativo, discriminatório? Quais palavras foram usadas como
forma de racismo / preconceito?
5- O público, ao efetuar a leitura do conto, consegue observar uma
história de aceitação da identidade afro-brasileira? Por quê?

Atividade aplicada durante a oficina do Pibid, realizada junto à turma do $1^{\circ} \mathrm{B}$ - matutino, formada por estudantes do Colégio Estadual Filinto Justiniano Bastos.

Fonte: Elaborado pelos autores.

Após a aplicação, analisamos as respostas dos estudantes. A respeito de algumas características, muitos dos alunos da turma não conseguiram responder satisfatoriamente às perguntas propostas. Porém, em duas das cinco características, grande parte da turma conseguiu responder de forma regular, apresentando justificativas para suas respostas. Os índices das respostas dos estudantes na atividade foram tabulados e estão dispostos no gráfico abaixo:

\section{Gráfico 1 - Respostas da atividade da oficina de Literatura Afro-Brasileira}

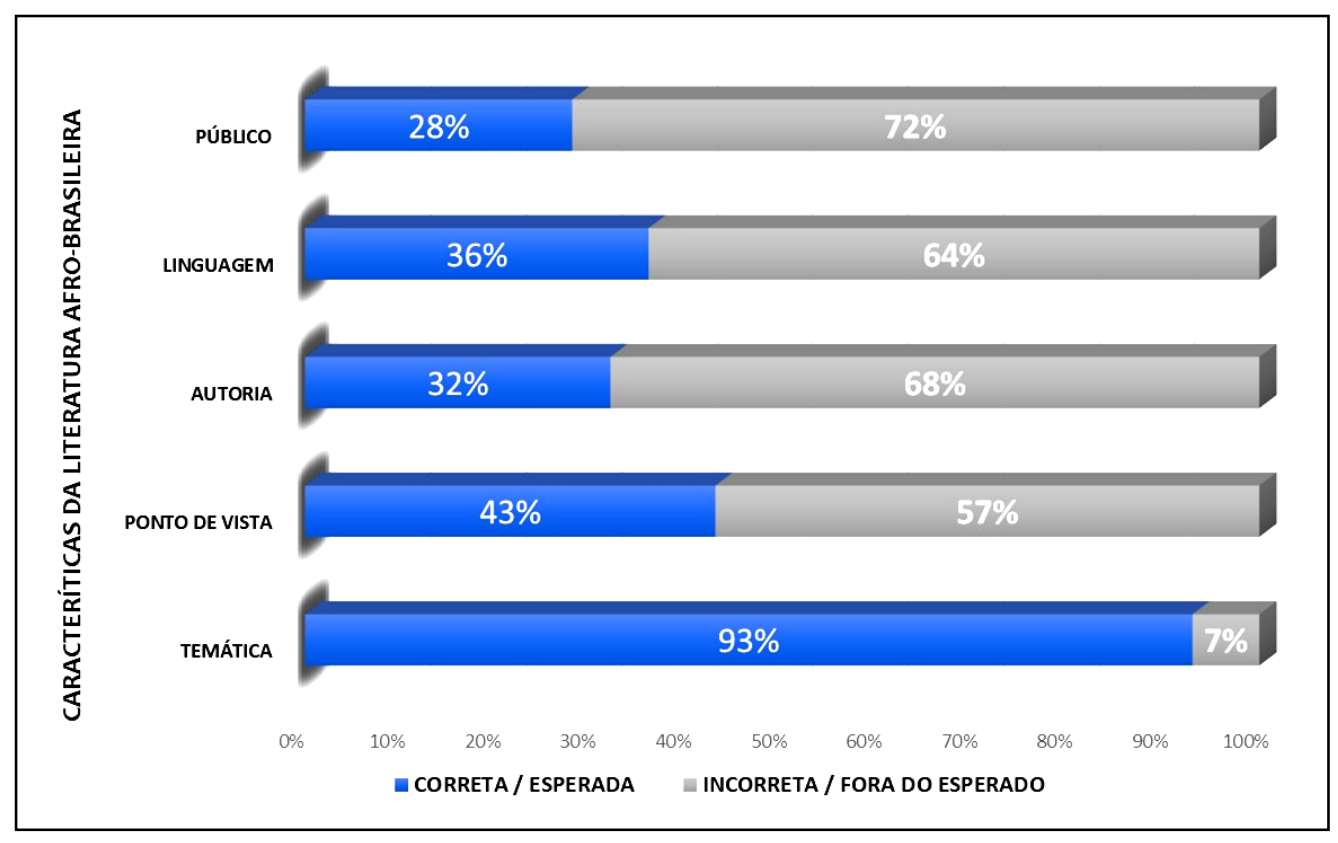

Fonte: Elaborado pelos autores. 
- Revista de Iniciação à Docência, v. 5, n. 2, 2020 -

Publicação: agosto, 2020 - ISSN 2525-4332

Diante dos dados apresentados, podemos chegar as seguintes constatações: quando a característica "temática" foi analisada pelos alunos, 93\% deles responderam corretamente. Entre as possíveis respostas corretas, esperava-se que os discentes apontassem que o conto "Pixaim" narra a história de uma garota negra vítima de racismo devido ao seu cabelo, chegando ao fato de sua mãe tentá-la "embranquecer" alisando suas madeixas com um produto químico.

Sobre a característica "ponto de vista", 43\% da turma respondeu dentro dos parâmetros esperados: a visão apresentada pelo conto evidencia o preconceito racial vivenciado por negros e afrodescendentes no Brasil. Na obra em questão, a personagem consegue superar o preconceito e afirmar a sua identidade afro-brasileira.

Em relação aos acertos dos demais pontos, os índices foram os seguintes: autoria $32 \%$ - aqui, abordar os aspectos relacionados à biografia da autora e seu engajamento com a população afro-brasileira estavam entre as possíveis respostas consideradas como corretas -; linguagem 36\%, o conto não apresenta nenhuma palavra de origem africana; e público 28\% - "Pixaim" leva ao leitor uma perspectiva de encorajamento e auto aceitação identitária. Fuga total desses aspetos considerados como respostas corretas configurouse como incorreto / fora do esperado. Apesar desses índices, nos sentimos otimistas em ter plantando nos alunos esse assunto tão importante para nossa sociedade.

\section{Resultados das oficinas: a descoberta da Literatura Afro-Brasileira}

Desde o início das oficinas observamos que os discentes pouco possuíam um contato com a Literatura Afro-Brasileira e autores concernentes. Indagados no início da oficina sobre esse assunto, poucos mencionaram os autores e o conceito de Literatura Afro-Brasileira. Mas, com o decorrer das aulas seguintes e um contato mais significativo com obras, textos, autores, e a definição em si da Literatura Afro-Brasileira, os alunos conseguiram assimilar e amadurecer repostas sobre o conceito e características dessa literatura.

Os resultados obtidos evidenciam que os discentes puderam aproveitar o contato proporcionado pelas oficinas do PIBID, considerando a temática inicial do projeto, ampliando e aprofundando conhecimentos que grande parte da turma ainda não possuía sobre a vertente literária afro-brasileira.

\section{Considerações Finais}

A árdua tarefa de enfrentar uma sala de aula repleta de adolescentes não é simples. O PIBID nos proporcionou um contato inestimável com a escola e suas demandas. Alguns desses contatos foram descritos neste relato e demonstram que a educação não é um trabalho simples, porém, a experiência é gratificante. Ver que os estudantes passaram a ter um conhecimento inicial com a Literatura Afro-Brasileira foi significativo, sobretudo no contexto em que vivemos: um país ainda fortemente marcado pelas discriminações étnicas. Abordamos a literatura que muitas pessoas desconhecem e a partir das oficinas 
- Revista de Iniciação à Docência, v. 5, n. 2, 2020 -

Publicação: agosto, 2020 - ISSN 2525-4332

aplicadas nessa turma do $1^{\circ}$ ano do Colégio Estadual Filinto Justiniano Bastos incentivamos a leitura, a valorização da Literatura Afro-Brasileira e o cumprimento às Leis 10.639/2003 e $11.645 / 2008$.

\section{Referências}

ARAUJO, R. S. Resenha: Nina África: contos de uma África menina para ninar gente de todas as idades. Opará: Etnicidades, Movimentos Sociais e Educação, Paulo Afonso, v. 6, n. 9, p. 74-76, 2018. Disponível em:

<http://www.revistas.uneb.br/index.php/opara/article/viewFile/OPARAV6N9_4/4942>. Acesso em: 31 mar. 2020.

BRANDÃO, A. P. (Coord.). Memória das palavras. Rio de Janeiro/RJ: Fundação Roberto Marinho, 2006.

CUNHA JR, H. C. In: VÁRIOS AUTORES. Cadernos Negros 1. São Paulo/SP: Edição dos Autores, 1978.

DUARTE, E. de A. Por um Conceito de Literatura Afro-Brasileira. In: . (Org.).

Literatura e afrodescendência no Brasil: antologia crítica. Belo Horizonte/MG: UFMG, 2011. p. 375-403.

EVARISTO, C. Vozes Mulheres. 2018. Disponível em: <http://www.letras.ufmg.br/literafro/autoras/24-textosdas-autora/s/923-conceicao-evaristo-vozes-mulheres $>$. Acesso em 18 out. 2018.

GUATTARI, F.; DELEUZE, G. O que é uma literatura menor? In: . Kafka: por uma literatura menor. Assírio \& Alvim, 2003, p. 38-56.

LEITE, G. de O. Literatura e Mitologia afro-baiana: encantos e percalços. In: GODINHO, L. F. R.; SANTOS, J. S. S. (Orgs.). Recôncavo da Bahia: educação, cultura e sociedade. Amargosa/BA: CIAN, 2007, p. 95-97

SOBRAL, C. P. In: RIBEIRO, E.; BARBOSA, M. (Orgs.). Cadernos Negros 24: contos afrobrasileiros. São Paulo/SP: Quilombhoje, 2011, p. 13-17. 